\title{
Retraction Note: Environmental regulation of PM2.5 in urban green vegetation and the influence of green technology progress based
} on remote sensing image

\author{
Chunling Zhang ${ }^{1} \cdot{\text { Yumei } X{ }^{1}}^{1}$ \\ Published online: 9 December 2021 \\ c) Saudi Society for Geosciences 2021
}

Retraction Note: Arabian Journal of Geosciences (2021) 14: 1066 https://doi.org/10.1007/s12517-021-07277-y

The Editor-in-Chief and the Publisher have retracted this article because the content of this article is nonsensical. The peer review process was not carried out in accordance with the Publisher's peer review policy. The authors have not responded to correspondence regarding this retraction.

The original article can be found online at https://doi.org/10.1007/ s12517-021-07277-y.

Yumei Xu

neauxym@neau.edu.cn

1 School of Public Administration and Law, Northeast Agricultural University, Harbin 150030, Heilongjiang, China 